\title{
The public sector as an adapter for digital innovation
}

\author{
Margarita Agafonova ${ }^{1}$, Elena Bautina ${ }^{1}$, Vera Poryadina $^{1,}{ }^{,}$, and Tatyana Likhacheva ${ }^{1}$ \\ ${ }^{1}$ Voronezh State Technical University, Moscovskiy prospect, 14, Voronezh, 394026, Russia
}

\begin{abstract}
The paper attempts to study the theoretical aspects of digitalization of the economy. Analysis of the current level of development of the digital economy in Russia is presented. An assessment of the current state of digital transformation of the public sector is made. Potential opportunities and threats from the digital economy in relation to the public sector are identified. The prospects for the digital transformation of the public sector economy are identified. The theoretical and practical significance of the work is determined by the novelty of the conclusions and a comprehensive study of the problem with the subsequent systematization of the data. The content of the paper, its main conclusions and provisions can be used both for further in-depth study of digital solutions and their impact on the economy, and for direct guidance on the implementation of digital technologies in the economy.
\end{abstract}

\section{Introduction}

The digital economy is a new reality. The existing way of life is gradually changing under the influence of digitalization. Some professions disappear and new ones appear every day. The purchasing power of the population is increasing; goods and services are becoming more and more accessible.

Digital transformation is one of the key drivers of economic growth. Therefore, the problem of studying and implementing digital technologies both in the private sector and in the public sector is becoming more acute.

Digitalization is a relatively new and little studied process. But nevertheless, this is a process that can no longer be stopped, which penetrates into all spheres of society and gradually becomes an integral part of our life. A large number of organizations devote their research to the analysis of the level of development of the digitalization of the economy: the UN, the WEF, the Cornell University consortium, the INSEAD School of Business and the World Intellectual Property Organization, the World Bank, consulting companies and others.

However, to date, there is no separate, comprehensive study on the digitalization of the public sector. Nowadays, there are only reports on monitoring the state of digitalization in the field of public administration, conducted by international and Russian organizations.

The relevance of the chosen topic is caused by a number of factors.

\footnotetext{
* Corresponding author: agaf-econ@yandex.ru
} 
First, the scarcity of scientific and practical research devoted to digitalization due to the novelty of the phenomenon. Despite the fact that a huge number of articles on the digital economy began to appear since 2016, there is still no comprehensive analysis of this issue. Insufficient knowledge of this topic is one of the factors that make it possible to call the topic of the digital economy relevant.

Secondly, there is a consensus that digitalization is a driver of economic growth, the fourth industrial revolution. However, at the moment, heads of companies and government agencies do not have a clear idea of the new opportunities for digitalization, and there are very few ideas on how to implement new technologies into practice. The public sector, with all its power, can become a locomotive for the introduction of digital technologies.

Studying various aspects of digitalization and their impact on the public sector is extremely important for the national economy. Identifying opportunities and threats from the digital transformation of the public sector will help make its functioning more efficient, analyzing the impact of digitalization on the economy will help to adjust the speed and characteristics of implementation in a particular area.

\section{Materials and Methods}

The digital economy (abbreviated: DE) has become one of the most discussed topics at various summits and conferences over the past few years. The introduction of new solutions is becoming a vital necessity in a competitive market.

Speaking about the process of digitalization of the economy and society, first of all, it is necessary to introduce certainty into the terminology. In the broadest sense, digitalization is usually understood as a socio-economic transformation initiated by the massive introduction and assimilation of digital technologies, i.e. technologies for the creation, processing, exchange and transmission of information [1]. If we refer to the legislative framework of the Russian Federation, specifically, to the decree of the President of the Russian Federation of 09.05.2017 No. 203 "On the Strategy for the Development of the Information Society in the Russian Federation for 2017 - 2030", we can find the following interpretation of this phenomenon: "The digital economy is an economic activity in which digital data is a key factor in production, processing large volumes and using the analysis results of which, in comparison with traditional forms of management, can significantly increase the efficiency of various types of production, technologies, equipment, storage, sale, delivery of goods and services".

The term "digital economy" was first used in 1995 by the American computer scientist Nicholas Negroponte. The scientist presented the digitalization process in the form of the transition from the movement of atoms to the movement of bits [2]. However, the process of the formation of the digital economy began several decades earlier.

A key factor of production in the digital economy is digital data, which is generated using modern technologies and which contribute to the formation of an information space, taking into account the need for obtaining high-quality and reliable information.

There are several key features and trends of digitalization.

Decentralization: small companies, individuals, consumers are starting to play a tangible role in economic and social enterprises.

The increasing use of intangible (Knowledge Based) capital, access to digital technologies, the sharing of resources make significant monetary contributions to business unnecessary. The definition of the possession of material property, control and management, profit, investment - these are questions of a new era.

Digitalization affects all sectors of the economy and social activity. In addition, DE empowers people in new areas, spawning new businesses and markets. 
The OECD is researching the changes that are taking place and has systematically proposed a number of initiatives. In one of the numerous studies, the essence of changes in various areas under the influence of digitalization is reflected. The main transformations are presented in Table 1.

Table 1. Changes in various spheres of society under the influence of digitalization and informatization [3]

\begin{tabular}{|l|l|}
\hline \multicolumn{1}{|c|}{ Sphere of analysis } & \multicolumn{1}{c|}{ The essence of changes/projects } \\
\hline Professional activity & Structural changes in professions \\
\hline Social capital & New opportunities for qualitative changes in education \\
\hline $\begin{array}{l}\text { Manufacturing and } \\
\text { entrepreneurship }\end{array}$ & $\begin{array}{l}\text { Industrial revolution; the emergence of new forms of } \\
\text { entrepreneurship }\end{array}$ \\
\hline Science and research & $\begin{array}{l}\text { Better collection and processing of information; more } \\
\text { widespread use }\end{array}$ \\
\hline Finance & $\begin{array}{l}\text { New financial technologies (e.g. algorithmic trading, shared } \\
\text { transaction ledgers); opportunities for automatic financial } \\
\text { recommendations }\end{array}$ \\
\hline Government services & More efficient delivery of public services \\
\hline Health care & $\begin{array}{l}\text { The use of data in healthcare makes this service more efficient } \\
\text { and more user-friendly }\end{array}$ \\
\hline Trade & $\begin{array}{l}\text { An increase in the amount of data that accompanies the } \\
\text { movement of goods; general development of trade; the } \\
\text { emergence of global production chains of enterprises }\end{array}$ \\
\hline Transport & $\begin{array}{l}\text { Prospects for the development of autonomous infrastructure, } \\
\text { great mobility }\end{array}$ \\
\hline Agriculture and fisheries & $\begin{array}{l}\text { Big data, the use of the Internet, drones and other digital } \\
\text { technologies have the potential to increase the productivity of } \\
\text { agriculture and fisheries }\end{array}$ \\
\hline Environment & $\begin{array}{l}\text { Possibilities of using alternative energy sources that are more } \\
\text { environmentally friendly, reducing the scale of its pollution, } \\
\text { preserving the diversity of biological species on the planet. At } \\
\text { the same time, the use of digital technologies is associated } \\
\text { with significant energy consumption }\end{array}$ \\
\hline
\end{tabular}

In general, today the breadth and depth of technological changes are fundamentally changing society, its usual ways and the entire system of production, decision-making and management in almost all spheres of the economy. The lines between man and machine are gradually being erased. Now these lines are blurred so far only where there is a need for repetitive labor-intensive processes. Against the background of the development of machines, the price of creative ideas and the value of people who generate these ideas will grow. Therefore, in the twenty-first century, we need a new look at the model of the socioeconomic development of the state and public administration in the conditions that are being shaped by the global digital revolution.

\section{Results}

Globally, the development goals of the digital economy in the Russian Federation are to improve the quality of life, ensure national security and the country's competitiveness. Achieving these goals depends on the participation of the public sector, which simultaneously acts as both the subject and the object of the digitalization process. In other words, the role of the public sector in the development of the digital economy, the importance of the state can hardly be overestimated. This role is [4]: 
- Transformation of state structures - change of management, organization of activities, interaction with other structures. Like the private sector, the state must become more flexible and adaptable.

- Creation of conditions for new technologies to have a positive impact on the economy of the country as a whole, on all its subjects. Unlike the private sector, the mission of the public sector is broad: the state cannot act only in the interests of the organizations and enterprises subordinate to it.

The factors influencing the development of the digital economy, or its drivers, according to the experts from the Russian Federal State Statistics Service (Rosstat), are the following:

- human capital (level of education and professional training of the population; information literacy of the population);

- innovation potential (characterizing the resource base of R\&D and innovation, the effectiveness of R\&D and innovation, institutional infrastructure environment);

- ICT - infrastructure and access (fixed telephony, mobile cellular communications, television and radio broadcasting, development of communication and data transmission networks, PC and Internet access, affordability of ICT services);

- economic environment (general state of the economy; availability of financial resources, purchasing power of the population, corporate consumers and the public sector);

- information industry;

- information security [5]

With regard to the state, the following areas of digitalization can be distinguished:

1. Translation of interdepartmental interactions and internal processes into a completely digital format, creation of convenient platforms for inter- and intradepartmental interaction. Public services are becoming fully digital and integrated with related departments, which ensures the speed of data transfer, reduces costs, and increases the efficiency of government agencies.

2. Creation of convenient platforms for interaction between the state and the population, the formation of special platforms for interaction between citizens and the state.

Now great opportunities for citizens to participate in solving state issues in electronic form are provided by social networks, crowdsourcing resources, Internet forums, portals for collecting signatures, which are becoming the leading platforms for discursive discussion of pressing social problems. This segment of public life (and the corresponding toolkit) is formed by the forces of not only government agencies, but also public organizations, as well as citizens themselves.

Social networks today are the foundation of human society, and digital technologies have increased the speed of the process of their formation. Social media fosters beneficial interactions from an economic point of view, becomes the basis for the collection and dissemination of information in case of emergencies and natural disasters, and fosters social change and citizen involvement in public life. According to analysts, social networks are an effective tool for spreading the ideas of democracy. Active involvement of citizens in solving socio-political and social issues allows state structures to function more efficiently, and the population has the opportunity to participate in making significant decisions, which contributes to an increase in citizens' satisfaction with the functioning of state bodies.

The interaction of government agencies with citizens and legal entities is becoming more convenient. This is also facilitated by the introduction of intuitive interfaces with access to public services. At the same time, the use of mobile applications as a channel of communication between the population and the state is growing. The basic principles of organizing work online are an individual approach to each citizen, planning interaction taking into account the user's needs, providing high-quality support and services to individual departments through a single channel. 
3. Digital identification.

Simple electronic identification systems, often using biometrics, have become a reliable platform for secure voting, banking, utility bills, access to social services, and more.

4. Formation and analysis of large data sets

The use of big data sets can significantly increase the efficiency and quality of public services, for example, by optimizing public transport routes, preventing crime, ensuring the targeting of social and medical assistance, improving the accuracy of modeling and forecasting, and more efficiently planning the construction of the necessary infrastructure.

5. Digital finance.

Mobile money and digital currency, online payments are technologies that can compensate for the imperfections of financial systems and make them more efficient. Electronic transfers reduce transfer costs. Digital finance helps to simplify the functioning of various government structures, their interaction with each other, as well as with citizens. Governments have been able to make payments and provide social benefits at a lower cost, reducing opportunities for fraud and money leakage. However, if financial regulations do not keep pace with advances in technology, such innovations run the risk of undermining the stability of the system as a whole.

One of the components of the public sector digitalization is the concept of e-government. The term "electronic government" (abbreviated: EG) describes the wide scope of application of information and telecommunication technologies in the political and administrative processes of the state [6].

E-government refers to the process of using information technologies (Internet, networks, computer and mobile technologies) by government bodies, which transforms relationships with citizens, business and other structures. According to World Bank experts, e-government serves a number of purposes, for example: ensuring better quality of services and wide access to information for citizens, more effective public administration, and strengthening interaction between government and business. An increase in the transparency of public administration, a decrease in the corruption component, a reorientation to the needs and interests of citizens, as well as a decrease in public spending and/or an increase in income are considered as results of the introduction of ICT in the public sphere [7].

\section{Discussions}

Digitalization is actively penetrating all sectors of the economy. The public sector has also become an adapter for new technologies. Digital transformation has affected both stateowned enterprises and the sphere of state and municipal administration. In addition, new technologies are being introduced in the spheres of health care, culture, education, which are also part of the public sector.

In this paper, the emphasis is on the analysis of the implementation of digital technologies in the sphere of public administration, therefore, the digitalization of other areas of the public sector will be only briefly discussed.

Government-owned organizations use the Internet, personal computers, servers and websites more intensively than other-owned organizations. Thus, $98.7 \%$ of state-owned organizations use the Internet in their activities (compared to $84.1 \%$ of private companies). Likewise, the share of government organizations using PCs, servers and websites is higher compared to private businesses. It can be concluded that the public sector is actively involved in the digitalization process.

State-owned companies are actively introducing and using advanced technologies. Innovative solutions are being introduced at state-owned large industrial enterprises. For capital-intensive industries (power generation, oil and gas production), Industry 4.0 
technologies can significantly improve efficiency, but this does not entail a radical transformation of the business model. For more labor-intensive industries, the optimization potential lies in improving the efficiency of the production process through in-depth analytics, automation and the use of the Internet of Things.

Large state financial companies are also trying to keep up with the times. Russian banks are «ready to jump», having a good opportunity to quickly transfer clients to modern service channels, mainly remote one. Moreover, digital transformation is driving the expansion and development of the product portfolio and the reduction of credit risks.

In the field of management, both at the level of production and at the level of the state, the following trends are currently observed: obtaining data in real time; management of economic processes based on automated analysis of big data; high speed of decision making; targeting a specific user. The digital ecosystem is understood as the center of synergy between the state, business and citizens.

Digitalization is successfully penetrating the educational environment. Thus, according to Rosstat data, the value of the key indicators used to assess the digitalization of the education sector in Russia has increased (with the exception of a number of indicators characterizing the use of ICT in the educational process and management of an educational institution of higher professional education). Significant growth of indicators is caused by a number of factors: first, the active policy of the state in relation to the penetration of figures into the educational process; secondly, initially low values of indicators.

The situation in the healthcare sector is similar: the values of indicators characterizing the level of digitalization in this area have increased significantly over 6 years. Information technologies are increasingly being used in Russian healthcare. Medical centers are gradually switching from paper medical records to electronic ones. At the same time, about $30 \%$ of patients use remote channels: telephone, Internet, mobile applications, while in 2011 , it was possible to make an appointment with a doctor only through the registration in the medical center. Now more than $90 \%$ of prescriptions are issued electronically, which significantly reduces the waiting time for an appointment with a doctor. Other cities and regions are also striving to introduce electronic systems like UMIAS.

Digitalization allows heads of medical institutions to use additional tools to control key performance indicators, such as the employment and duration of appointments of individual doctors, the load of the institution as a whole, the availability of appointments, the number of complaints, the waiting time of patients, and financial indicators.

New technologies are actively penetrating into the sphere of culture. Significant improvements are visible. However, at the moment, the digitalization of this area cannot be called successful. Thus, not all libraries, museums and theaters have personal computers. There are relatively few institutions in the country that have their own website on the Internet $(37.3 \%)$. Now active work is underway to eliminate the backlog in the cultural sphere.

Significant problems are observed in terms of the distribution of works: not all digitized documents/works are available for review. In the field of culture, digital platforms are underdeveloped. There is still an ongoing conflict between representatives of the IT industry and copyright holders.

\section{Conclusion}

Globally, the development goals of the digital economy in the Russian Federation are to improve the quality of life, ensure national security and the country's competitiveness. Achieving these goals depends on the participation of the public sector, which simultaneously acts as both the subject and the object of the digitalization process. 
Digitalization today is a necessary condition for competitive activity. Digitalization allows increasing labor productivity, reducing production costs; increasing the competitiveness of companies; creating new jobs; more fully meeting the needs of people and having an impact on reducing poverty and social inequality.

Speaking about the effect of the introduction of digital technologies into government bodies and local self-government bodies, the following results of the use of ICT can be highlighted: increased efficiency and transparency of institutions at all levels; reducing the corruption component; increasing the availability of information; guarantee of adoption of decisions that meet the needs of society by state and local authorities; protection of fundamental freedoms of citizens.

At the same time, digitalization of the public sector carries a number of threats: potential surveillance of citizens, violation of private life; reduced data security; a threat to the country's "digital sovereignty"; decrease in the number of jobs of low and medium qualifications; increasing the complexity of business models and interaction schemes; inconsistency of existing legislation with the needs of society.

Digitalization is given great importance at the government level. Various state programs are devoted to the development of digital technologies, including projects to eliminate the digital divide, develop public electronic services, involve citizens in the process of making socially significant decisions, create comfortable cities for life, and expand the electronic procurement system.

Having analyzed the current level of digitalization of the public sector, one can single out the following areas for creating favorable conditions for the further transformation of the public sector: reforming the education system; improving the infrastructure environment; introducing digital technologies in public authorities and local governments; creating a favorable investment climate; investing in research and development; promoting innovation; improving information security.

Russia is a promising country in terms of the development of digital technologies. Experts do not exclude that Russia may become a leading country in the field of digitalization in the near future.

In the course of this work, the topic of the impact of digitalization on the public sector was widely covered. However, this problem needs to be studied more thoroughly, in particular, at the government level, using closed data from various state and municipal authorities, in order to apply the results obtained in practice.

\section{References}

1. E. Avdeeva, T. Davydova, N. Skripnikova, L. Kochetova, E3S Web of Conferences, 110, 02139 (2019)

2. Negroponte, Nicholas Being Digital, New York: Alfred A. Knopf (1995)

3. Z. Li, J. Ji, W. Yuan, Z. Song, X. Ren, M. Uddin, K. Luo, X. Zhao, Energy, 194 (2020) https://doi.org/10.1016/j.energy.2019.116776

4. L. Buckalew, M. Wade, J. Macaulay, T. Jelassi, Public Sector and the Digital Vortex: How Government Organizations Can Harness Digital Disruption for Positive Change, IMD International Institute for Management Development, June 2017

5. S. A. Tinkov, E. V. Tinkova Indicator to Assess the Level of Development of Productive Capacity and Quality of Life. In: Solovev D. (eds) Smart Technologies and Innovations in Design for Control of Technological Processes and Objects: Economy and Production. FarEastCon 2018. Smart Innovation, Systems and Technologies, Springer, Cham. 139 (2019) https://doi.org/10.1007/978-3-030-18553-4_69 
6. K. E. Kovalenko, S. Y. Bakhvalov, A. O. Zekiy, V. V. Vikulina, S. A. Tinkov, T. V. Tkacheva, Key indicators of innovation activity of Russia (from 2011 to 2017). Journal of Entrepreneurship Education, 22(3), 1-7 (2019)

7. O. V. Konina, S. A. Tinkov, E. V. Tinkova, Management in Higher Education Based on "Smart Technologies": Digital Managerial Staff vs. Artificial Intelligence. Lecture Notes in Networks and Systems, 155, 1738-1745 (2021)

8. T. V. Alesinskaya, D. V. Arutyunova, V. G. Orlova, I. V. Ilin, S. V. Shirokova, Conception BSC for investment support of port and industrial complexes Academy of Strategic Management Journal, 16(1), 10-20 (2017)

9. I. V. Ilin, A. V. Izotov, S. V. Shirokova, O. V. Rostova, A. I. Levina, Method of decision making support for it market analysis Proceedings of 2017 20th IEEE International Conference on Soft Computing and Measurements, SCM 2017, 7970732, 812-814 (2017)

10. L. Pushkareva, M. Pushkarev E3S Web of Conferences 164, 10027 (2020) doi:10.1051/e3sconf/202016410027 